Farm animal welfare - who writes the rules?

Occasional Publication No. 23 - British Society of Animal Science 1999

edited by A. J. F. Russel, C. A. Morgan, C. J. Savory, M. C. Appleby and T. L. J. Lawrence

\title{
Sucking position and duration in natural and adopted calves
}

\author{
H. D. Randle \\ Department of Agriculture and Food, Seale-Hayne Faculty, University of Plymouth, Newton Abbot TQ12 6NQ
}

\section{Introduction}

It is possible for domesticated beef cattle to adopt an additional calf. A method of double suckling in which the additional calf is adopted by the cow was developed by Kiley-Worthington (1976). This method differs from those such as multiple suckling (e.g. Hudson, 1977) which are based on fostering and often require substantial amounts of human resources. It is well known that suckling plays a fundamental rôle in the reinforcement of the motheryoung bond in cattle (Le Neindre, 1982). In the case of double suckling it is particularly important that the additional calf (the adoptee) is permitted to suck. However, to achieve this the adoptee must behave appropriately to ensure acceptance by the dam. Most cows will not allow calves other than their own natural calves to suck them (Price et al., 1986). Once the natural calf starts sucking, milk is let down by the cow (Orihuela, 1990) and is potentially available to the adoptee. There is some evidence that adoptee calves employ an 'opportunistic' strategy in order to obtain milk. One aspect of this is the initiation of suckling bouts. Adoptees learn to synchronize their sucking with that of the natural calf, i.e. they wait for the natural calf to suck before starting to suck themselves. The typical position assumed by a single sucking, natural calf is 'parallel inverse', where the calf's head faces the mother's tail and there is maximum body contact between the dam and calf (Le Neindre, 1982). However, Spinka and Illman (1992) report that adopted calves do not assume this position. A typical suck position taken up by alien calves is between the cow's hind legs, a position frequently assumed by single sucking, natural, calves near the end of a sucking bout (Le Neindre, 1982). Sucking duration typically declines with increasing calf age (Le Niendre, 1982; Kiley-Worthington and de la Plain, 1983; Nakanshi et al., 1993). The work reported in this paper aims to compare the sucking positions and durations achieved by adopted calves with those exhibited by the natural calves.

\section{Material and methods}

A total of 13 trios were observed, each consisting of a South Devon cow, her homebred natural calf and an adopted calf. Adoptions were carried out using the method developed by Kiley-Worthington (1976). For further details see Randle (1996b).

In group 1, six trios were observed for the 1st week of the adoption and week 3 post adoption. In group 2, seven trios were observed during the 1st week of the adoption and for the 1st week of month 5 post adoption. These observation periods covered all suckling sessions which occurred between 06.00 and $21.00 \mathrm{~h}$. Observations included all of the behaviours exhibited by the dam and both the natural and adopted calves. These were recorded simultaneously. The full list of behaviours recorded during a suckling session is given in Randle (1999b) All of the different positions assumed by both the natural and adopted calves (for at least $5 \mathrm{~s}$ ) throughout a suckling session were recorded. Sucking positions were categorized as inside - focal calf (where the focal calf was either the natural or the adoptee whichever was being recorded) on the inside of the other calf, parallel and adjacent to the dam, or outside - focal calf on the outside of the other calf, parallel but not adjacent to the dam, or sucking from between the dam's hind legs. The sucking duration exhibited by both calves in each position was also recorded.

At the end of the four observation periods the success of the adoptions were rated using the fivepoint system developed by Kiley-Worthington and de la Plain (1983). The detailed descriptions of $R$ (rejected), F1 (level one fostering), F2 (level two fostering), A1 (level one adoption) and A2 (level two adoption) are given by Randle (1996b).

The proportion of sucking time spent in the inside sucking positions by naturals and adoptees was subjected to ANOVA. The durations of sucking by naturals and adoptees in the inside and outside positions were subjected to a two-way ANOVA. Two further three-way ANOVAs were performed in order to examine the influence of calf type (natural, adoptee), sucking position (inside, outside) and time (week 1 , week 3 in group 1; week 1 , month 5 in group 2) on sucking duration. 
Table 1 Proportion of sucking time spent in the inside positions by natural and adopted calves (upper) and mean suckling duration (min) exhibited by natural and adopted calves in the inside and outside sucking positions (lower) for both group 1 and group 2

\begin{tabular}{|c|c|c|c|c|c|}
\hline Sucking & \multicolumn{2}{|c|}{ Natural calves } & \multicolumn{2}{|c|}{ Adopted calves } & Significance \\
\hline \multicolumn{6}{|c|}{$\begin{array}{l}\text { Proportion of time } \\
\text { inside }\end{array}$} \\
\hline Group 1 & \multicolumn{2}{|c|}{0.92} & \multicolumn{2}{|c|}{0.33} & $* * *$ \\
\hline Group 2 & \multicolumn{2}{|c|}{0.74} & \multicolumn{2}{|c|}{0.31} & $* * *$ \\
\hline \multicolumn{6}{|c|}{$\begin{array}{l}\text { Duration of } \\
\text { sucking Inside Outside }\end{array}$} \\
\hline Group 1 & 5.49 & 1.48 & 3.55 & $3 \cdot 30$ & * \\
\hline Group 2 & 4.99 & $2 \cdot 05$ & $3 \cdot 13$ & $2 \cdot 62$ & $*$ \\
\hline
\end{tabular}

\section{Results}

At the end of the 1st week of the adoption 12 of the 13 adoptions were considered to be successful, i.e. the cow had 'adopted' the second calf and no human intervention was necessary to ensure successful suckling (see Table 1: Randle, 1999b).

In total 409 suckling sessions were observed, in group 1, 107 during week 1, 94 during week 3 and in group 2, 134 during week 1 and 74 during the 1st week of month 5 . In both groups the natural calves spent a significantly greater proportion of time sucking from the inside positions (inside the other calf, parallel and adjacent to the dam) than the adopted calves $(P<0 \cdot 001)$ (Table 1$)$. In both groups there was a significant interactive effect of calf type (natural, adoptee) and sucking position (inside, outside) on the duration of sucking $(P<0.05)$. The natural calves sucked for significantly longer when in the inside positions compared with adopted calves in either the inside or outside positions $(P<0.05)$, whilst the adopted calves exhibited significantly longer sucking durations when in the outside positions (outside of the natural calf, not adjacent to the dam, or between the dam's hind legs) than the natural calves when they were in the outside positions $(P<0.05)$ (Table 1$)$. There was a significant interactive effect of calf type (natural, adoptee), sucking position (inside, outside) and time (week 1, week 3 ) in group 1 but not in group 2 (Table 2). The adoptees achieved their longest, uninterrupted sucking durations in week 3 post adoption when suckling from the outside positions.

\section{Discussion}

\section{Double suckling with adoption}

The double suckling with adoption method used was successful. One of the 13 adoptions failed, although the additional calf was allowed to suck if the dam was under close human supervision.

\section{Suckling positions and durations}

The sucking behaviour of all of the calves studied was typical of calves in a beef suckler system. Since the adopted calves always sucked at the same time as the natural calves it can be concluded that the welfare of the adoptees was not compromised by being reared by an adoptive dam (Lidfors et al., 1993). At week 3 post adoption the differentiation of sucking positions assumed by natural and adoptee calves was pronounced. Natural calves sucked from the typical parallel, inverse, positions (Le Neindre, 1982) which afforded maximum bodily contact with the dam, whilst the adoptee calves sucked from positions resulting in less bodily contact with the dam, usually on the outside of the natural calf. It appears that the adoptees learnt that it was more effective to suck from the outside positions and utilized this as part of an opportunistic strategy (coupled with waiting for the natural calf to initiate the sucking, see Randle (1999b) to obtain milk. This suggestion is supported by the longer sucking durations achieved by adoptees when in the outside positions at week 3 post adoption when the trio was not subject to human supervision. The nonsignificant interaction between calf type, sucking

Table 2 Mean sucking duration (min) exhibited by natural and adopted calves, in the inside and outside sucking positions in week 1 (groups 1 and 2) and week 3 (group 1) and the 1st week of month 5 (group 2) of the adoption

\begin{tabular}{|c|c|c|c|c|c|}
\hline Group & \multicolumn{2}{|c|}{ Natural calves } & \multicolumn{2}{|c|}{ Adopted calves } & Significance \\
\hline $\begin{array}{l}\text { Duration of sucking ( } \mathrm{min} \text { ) } \\
\text { Sucking in inside position } \\
\text { Sucking in outside position }\end{array}$ & $\begin{array}{c}\text { Week } 1 \\
4.85 \\
1.99\end{array}$ & $\begin{array}{c}\text { Week } 3 \\
6.14 \\
0.96\end{array}$ & $\begin{array}{c}\text { Week } 1 \\
4 \cdot 18 \\
2 \cdot 34\end{array}$ & $\begin{array}{c}\text { Week } 3 \\
2 \cdot 93 \\
4 \cdot 25\end{array}$ & * \\
\hline $\begin{array}{l}\text { Group } 2 \\
\text { Duration of sucking (min) } \\
\text { Sucking in inside position } \\
\text { Sucking in outside position }\end{array}$ & $\begin{array}{c}\text { Week } 1 \\
4 \cdot 74 \\
2 \cdot 62\end{array}$ & $\begin{array}{l}\text { Week } 1 \text {, month } 5 \\
\begin{array}{l}5 \cdot 24 \\
1 \cdot 48\end{array}\end{array}$ & $\begin{array}{c}\text { Week } 1 \\
3 \cdot 75 \\
2 \cdot 67\end{array}$ & $\begin{array}{l}\text { Week } 1 \text {, month } 5 \\
\begin{array}{c}2.51 \\
2.57\end{array}\end{array}$ & \\
\hline
\end{tabular}


position and time (week $1 v$, the 1st week of month 5 post adoption) in group 2 was likely to have been due to occurrences of cross sucking (Randle, 1999a).

\section{Acknowledgements}

This work was undertaken as part of a Ph.D. at the University of Exeter. Dr Kiley-Worthington and $\mathrm{Mr} \mathrm{C}$. Rendle are thanked for their help and guidance with this work.

\section{References}

Hudson, S. 1977. Multi-fostering of calves onto nurse cows at birth. Applied Animal Ethology 3: 57-63.

Kiley-Worthington, M. 1976. Fostering and adoption of beef cattle. Digest - British Cattle Breeders Club 31: 42-55.

Kiley-Worthington, M. and de la Plain, S. 1983. The behaviour of beef suckler cattle (Bos taurus). Birkhauser Verlag, Basal.

Le Neindre, P. 1982. Cow-calf relationships: the effects of management type. In Welfare and husbandry of calves (ed. J. P. Signoret), pp. 5-15. Martinus Nijhoff, London.

Lidfors, L. M., Jensen, P. and Algers, B. 1993. Temporal patterning of suckling bouts in free ranging beef cattle. Proceedings of the 1993 Society for Veterinary Ethology congress, Berlin.
Nakanshi, Y., Maehara, Y., Masuda, Y. and Umetsu, R. 1993. Some behavioural aspects of cow-calf relationships in a herd of beef cattle in semi-confinement. Journal of the Faculty of Agriculture, Kyushu University 37: 219-226.

Orihuela, A. 1990. Effect of calf stimulus on the milk yield of Zebu type cattle. Applied Animal Behaviour Science 26: 187-190.

Price, E. O., Smith, V. M., Thos, J. and Anderson, G. S. 1986. The effects of twinning and maternal experience on maternal-filial social relationships in confined beef cattle. Applied Animal Behaviour Science 15: 137-146.

Randle, H. R. 1996a. Cross-suckling in beef suckler cows with natural and adopted calves. In Farm animal welfare who writes the rules? (ed. A. J. F. Russel, C. A. Morgan, C. J. Savory, M. C. Appleby and T. L. S. Lawrence), pp. 122-124. British Society of Animal Science occasional publication no. 23.

Randle, H. R. 1996b. Initiation of suckling in suckler cows with natural and adopted calves. In Farm animal welfare who writes the rules? (ed. A. J. F. Russel, C. A. Morgan, C. J. Savory, M. C. Appleby and T. L. S. Lawrence), pp. 116-119. British Society of Animal Science occasional publication no. 23.

Spinka, M. and Illman, G. 1992. Suckling behaviour of young dairy calves with their own and alien mothers. Applied Animal Behaviour Science 33: 165-174. 